\title{
Lactate level during cardiopulmonary bypass as a predictor of postoperative outcomes in adult patients undergoing cardiac surgery
}

\author{
Satoko Noguchi", Junichi Saito, Eiji Hashiba, Tetsuya Kushikata and Kazuyoshi Hirota
}

\begin{abstract}
Background: It has been reported that prolonged intensive care unit (ICU) stay after cardiac surgery is associated with poor patient outcome. In addition, prolonged stay can block the efficient use of ICU beds with an increase in expenditure of

health-care costs. The aim of the present study was to retrospectively determine which pre- and intra-operative factors could significantly affect ICU-free survival days (IFSD) which has been suggested to reflect postoperative patients' outcome, as well as variables significantly associated with the main predictors of IFSD.

Findings: We reviewed anesthesia charts and medical records of 145 patients undergoing cardiac surgery under cardiopulmonary bypass (CPB) in our hospital from January 2014 to October 2015, and 72 patients' records were finally used for the analysis. IFSD was a median of 25 days (95\% Cl 24-26). The multiple regression analysis indicated that preoperative estimated glomerular filtration rate, differences between preoperative mean arterial pressure and mean CPB pressure, and blood lactate level at $2 \mathrm{~h}$ after CPB (CPB-2 $\mathrm{h}$ ) were independently associated with IFSD ( $\beta$ regression coefficients $0.086,-0.083$, and -3 . 601 , respectively).
\end{abstract}

Conclusion: In addition to preoperative renal function and differences between preoperative MAP and CPB pressure, the lactate level at CPB-2 h could be a major predictor of postoperative outcome in patients undergoing cardiac surgery.

Keywords: Blood lactate level, Cardiac surgery, ICU-free survival days

\section{Findings}

\section{Background}

It has been reported that prolonged intensive care unit (ICU) stay after cardiac surgery is associated with poor patient outcome $[1,2]$. As prolonged ICU stay has also been reported to cause a significant decrease in longterm survival, determination of risk factors related to the prolonged ICU stay may be helpful to improve patients' outcome by avoiding these risk factors. In addition, prolonged stay can block the efficient use of ICU beds, may result in postponement of other operations, and also

* Correspondence: satko1110@yahoo.co.jp

Department of Anesthesiology, Hirosaki University Graduate School of

Medicine, 5 Zaifucho, Hirosaki 036-8562, Japan increases expenditure of health-care costs $[1,2]$. The use of life-support equipments such as ventilator and renal replacement system can particularly cause excessive expenditure in the ICU [3].

When patients die in a short period in the ICU, length of ICU stay (LOS) becomes shorter. Thus, as the LOS may not reflect patient's prognosis and severity of an illness, "ICU-free survival days" is now widely used as a better index than LOS for the outcome study $[4,5]$.

The aim of the present study was to retrospectively determine which pre- and intra-operative factors could significantly affect ICU-free survival days. 


\section{Materials and methods Study subjects}

This is a retrospective observational study approved by the Medical Ethics Committee of Hirosaki University Graduate School of Medicine (approval number 2015-168). There were 145 patients undergoing elective cardiac surgery under $\mathrm{CPB}$ in our institution between January 2014 and October 2015. As the following patients were excluded: patients under 18 years old, receiving on-pump beating procedure or circulatory arrest, and with $\mathrm{CPB}$ duration less than $120 \mathrm{~min}, 72$ patients' records were finally used for the analysis.

\section{Anesthesia and CPB management}

Anesthesia was induced and maintained using total intravenous anesthesia with propofol 1-5 $\mathrm{mg} / \mathrm{kg} / \mathrm{h}$, ketamine $0.5-2 \mathrm{mg} / \mathrm{kg} / \mathrm{h}$, fentanyl $15-25 \mu \mathrm{g} / \mathrm{kg}$, and intermittent $10 \mathrm{mg}$ rocuronium in all cases. After tracheal intubation, the lungs were ventilated with intermittent positive-pressure ventilation under $\mathrm{F}_{\mathrm{I}} \mathrm{O}_{2}$ of 0.3 to 1 which was dependent on oxygenation status. Vasoactive agents and inotropics were administrated to maintain stable hemodynamics when needed. The whole-blood activated coagulation time (ACT) was maintained greater than $400 \mathrm{~s}$ with intermittent intravenous heparin administration during $\mathrm{CPB}$. The $\mathrm{CPB}$ circuit was primed with colloid solutions at variable volumes. Cold crystalloid cardioplegia was administrated in an antegrade fashion every $30 \mathrm{~min}$ during the cross-clamping period or whenever electrical activity resumed. During $\mathrm{CPB}$, the following conditions were maintained: a mild hypothermia of $32-34{ }^{\circ} \mathrm{C}$, nonpulsatile flow at $2.2-$ $2.6 \mathrm{~L} / \mathrm{min} / \mathrm{m}^{2}$, mean perfusion pressure of $60-70 \mathrm{mmHg}$, and hematocrit (Hct) $>22 \%$. To keep target mean perfusion pressure during $\mathrm{CPB}$, vasopressor administration and/or increasing perfusion flow were performed. At the end of $\mathrm{CPB}$, protamine was administrated as required to return the $\mathrm{ACT}$ to the baseline values. Intra-operative blood salvage was also performed in most cases.

\section{Data collection and definitions}

The following available data were collected from each patient's record: age, sex, body weight, height, comorbidity (hypertension, diabetes, kidney injury, cerebrovascular diseases), current smoking and history of cardiac surgery, preoperative estimated glomerular filtration rate (eGFR), preoperative serum brain natriuretic peptide, New York Heart Association class, left ventricular ejection fraction (\%) estimated by echo-cardiography or angiography, type of operation, $\mathrm{CPB}$ data (CPB duration, aortic cross-clamping duration, nadir Hct, nadir temperature, perfusion pressure, mean flow), blood transfusions, preoperative vasoactive medication, LOS, and postoperative morbidity and mortality. Postoperative morbidity was defined as the following: renal complications (more than "injury" of RIFLE criteria for acute kidney injury (AKI)); respiratory complications (mechanical ventilation longer than $24 \mathrm{~h}$ with no apparent cardiac reason, requirement of noninvasive positive pressure ventilation or high-flow nasal cannula after tracheal extubation, acute respiratory distress syndrome); neurologic complications (coma or new focal neurologic deficit) [6]; cardiovascular complications (cardiac arrest, the requirement of percutaneous cardiopulmonary support (PCPS)); and requirement of surgical hemostasis. Blood lactate was measured by an arterial blood gas analyzer (ABL 800, Radiometer Co., Copenhagen, Denmark). After CPB was started, blood lactate was measured every $1 \mathrm{~h}$. Average mean arterial pressure (MAP) was obtained from three preoperative blood pressure readings: on admission, in the day before surgery, and just before induction of general anesthesia was defined as baseline MAP [7]. Mean CPB pressure and flow were also defined as the average of MAP and flow reading at every $30 \mathrm{~min}$ during $\mathrm{CPB}$. Ratio of $<\mathrm{CPB} 60$ or $50 \mathrm{mmHg}$ was defined as the rate of the duration lower than 60 or $50 \mathrm{mmHg}$ during CPB. ICU-free survival days was determined as the reminder to subtract LOS from 28 days. The criteria of ICU stay for post-cardiac surgical patients were the following: unstable respiration without any respiratory assist, using vasopressors, or needing renal replacement therapy. The discharge criteria of ICU were the following: stable respiration without orotracheal tube and maintaining $\mathrm{SpO}_{2}>92 \%$ without noninvasive positive pressure, stable circulation with no requirement of hemodynamic monitoring and maintaining systolic blood pressure $>90 \mathrm{mmHg}$ without vasoactive agents, and no requirement of compensation of acute abnormal laboratory values.

\section{Outcome and statistical analyses}

To determine which pre- and intra-operative factors could affect the ICU-free survival days, we performed univariate analysis to find candidate factors $(p<0.05)$ and then did multivariate regression analysis (SPSS 24.0, SPSS Inc., Chicago, IL, USA) by stepwise method. Data are presented as regression coefficient with $95 \%$ confidence intervals (CI). Other data were shown as median [25\% quartile-75\% quartile] or $n$ (\%). A $p<0.05$ was considered statistically significant.

\section{Results}

Preoperative and intra-operative demographics are depicted in Tables 1 and 2, respectively. ICU-free survival days in our study was a median of 25 days (95\% CI 24-26). There were 19 patients $(26.4 \%)$ who had at least one postoperative complications, 3 patients with renal complications, 12 patients with respiratory complications, 2 patients with neurologic complications, 3 patients with cardiovascular 
Table 1 Preoperative patient demographics

\begin{tabular}{|c|c|}
\hline Variable & Data \\
\hline Age (years) & $66.5[60.5-73.0]$ \\
\hline Weight (kg) & $53.2[48.0-60.3]$ \\
\hline Body mass index $\left(\mathrm{kg} / \mathrm{m}^{2}\right)$ & $22.3[20.2-23.6]$ \\
\hline Body surface area $\left(\mathrm{m}^{2}\right)$ & $1.52[1.43-1.63]$ \\
\hline Gender: male (\%) & $34(47.2)$ \\
\hline Hypertension (\%) & $49(68.0)$ \\
\hline Diabetes (\%) & $12(16.7)$ \\
\hline Dyslipidemia (\%) & $26(36.1)$ \\
\hline Current smoking (\%) & $29(40.3)$ \\
\hline Previous stroke (\%) & $18(25.0)$ \\
\hline Chronic dialysis (\%) & $9(12.5)$ \\
\hline Previous cardiac surgery (\%) & $8(11.1)$ \\
\hline Preoperative eGFR $\left(\mathrm{ml} / \mathrm{min} / 1.73 \mathrm{~m}^{2}\right)$ & $54.1[44.1-69.1]$ \\
\hline Preoperative BNP (pg/ml) & $253[87-496]$ \\
\hline NYHA class I/II/III/IV & $16 / 45 / 10 / 1$ \\
\hline Left ventricular ejection fraction (\%) & $61.5[50.7-70.6]$ \\
\hline Preoperative systolic blood pressure $(\mathrm{mmHg})$ & 131 [116-141] \\
\hline Preoperative diastolic blood pressure $(\mathrm{mmHg})$ & $68[60-76]$ \\
\hline Preoperative mean arterial pressure $(\mathrm{mmHg})$ & 87 [82-97] \\
\hline Preoperative $\beta$-blocker (\%) & $19(26.4)$ \\
\hline Preoperative anticoagulant (\%) & $29(40.3)$ \\
\hline Preoperative antiplatelet drug (\%) & $12(16.7)$ \\
\hline \multicolumn{2}{|l|}{ Type of operation } \\
\hline Single valve surgery (\%) & $43(59.7)$ \\
\hline Complex valve surgery (\%) & $16(22.2)$ \\
\hline CABG and valve surgery (\%) & $9(12.5)$ \\
\hline Other (\%) & $4(5.6)$ \\
\hline
\end{tabular}

Data were shown as median [25\% quartile-75\% quartile] or $n$ (\%) eGFR estimated glomerular filtration rate, BNP brain natriuretic peptide, NYHA New York Heart Association

complications, and 4 patients required surgical hemostasis. And there were two patients $(2.8 \%)$ who had died in ICU.

The univariate analysis indicated that ICU-free survival days could significantly be associated with preoperative eGFR, CPB duration, differences between preoperative MAP and mean CPB pressure, and blood lactate level measured $2 \mathrm{~h}$ after CPB started (CPB-2 h) (Table 3).

In our multivariate linear regression model including possible confounders, preoperative eGFR, differences between preoperative MAP and mean $\mathrm{CPB}$ pressure, and blood lactate level at $2 \mathrm{~h}$ after CPB were independently associated with ICU-free survival days (Table 4).

\section{Discussion}

Our retrospective analysis suggests that preoperative eGFR, differences between preoperative MAP and mean $\mathrm{CPB}$ pressure, and blood lactate level at CPB-2 $\mathrm{h}$ were
Table 2 Intra-operative characteristics

\begin{tabular}{ll}
\hline Variable & Data \\
\hline CPB duration (min) & $198[167-232]$ \\
Aortic cross-clamping duration (min) & $133[112-161]$ \\
Nadir hematocrit on CPB (\%) & $24.1[20.5-27.8]$ \\
Nadir temperature on CPB $\left({ }^{\circ} \mathrm{C}\right)$ & $34.0[33.0-34.4]$ \\
Mean CPB pressure $(\mathrm{mmHg})$ & $55.0[49.7-60.5]$ \\
Ratio of $<\mathrm{CPB}$ pressure $60 \mathrm{mmHg}(\%)$ & $65.7[40.0-89.9]$ \\
Ratio of <CPB pressure $50 \mathrm{mmHg}(\%)$ & $26.0[9.2-47.6]$ \\
Preoperative MAP-mean CPB pressure & $32.0[12.7-51.3]$ \\
Mean CPB flow (L/min) & $3.77[3.48-4.13]$ \\
Mean CPB flow index (L/min/m $\left.{ }^{2}\right)$ & $2.49[2.41-2.55]$ \\
Vasopressors during CPB (\%) & $23(31.9)$ \\
Transfusions during CPB with RBCs (\%) & $26(36.1)$ \\
Transfusions during CPB with FFPs (\%) & $20(27.8)$ \\
Lactate level at CPB-0 h (mmol/L) & $0.8[0.6-1.0]$ \\
Lactate level at CPB-1 h (mmol/L) & $1.1[0.8-1.4]$ \\
Lactate level at CPB-2 h (mmol/L) & $1.3[1.0-1.7]$ \\
\hline
\end{tabular}

Data were median [25\% quartile-75\% quartile] or $n(\%)$, ratio of $<$ CPB pressure ${ }^{* *} \mathrm{mmHg}(\%)$ : (duration of lower than **mmHg during $\mathrm{CPB} /$ total (PB time) $\times 100$

CPB cardiopulmonary bypass, MAP mean arterial pressure, CPB-\#h \# $\mathrm{h}$ after CPB started

associated with ICU-free survival days in the multivariate analysis.

The increase in blood lactate during CPB is well known in patients undergoing cardiac surgery due to variable reasons such as peripheral circulatory failure, hemodilution, or using catecholamine [8-10]. In addition, high blood lactate levels during perioperative period have been reported to be associated with worse outcomes including mortality [9-17]. Previous studies showed that early postoperative hyperlactatemia was more sensitive predictor of mortality and morbidity for patient undergoing cardiac surgery under $\mathrm{CPB}$ than late hyperlactatemia during ICU stay $[10,18]$. It was also reported that the maximum lactate level during cardiac surgery after CPB was significantly associated with LOS [9] and ICU-free survival days [19]. Early postoperative hyperlactatemia was associated with a low oxygen delivery during CPB [9-12]. Thus, the proper managements of CPB could avoid the increase in blood lactate levels. Although previous studies showed that the highest lactate level during $\mathrm{CPB}$, its level at the end of $\mathrm{CPB}$, or its level at the postoperative period could be related to worse postoperative outcomes, there is no report showing that lactate level at some time point during $\mathrm{CPB}$ could be the predictor of postoperative impaired outcome. In this regard, the present study may be the first report. In addition, the present data suggest that early therapeutic intervention in accordance with blood lactate levels during $\mathrm{CPB}$ might be important to avoid worth 
Table 3 Univariate association of preoperative and intraoperative variables with the ICU-free survival days

\begin{tabular}{|c|c|c|}
\hline Variable & $\begin{array}{l}\text { Regression coefficient } \\
{[95 \% \mathrm{Cl}]}\end{array}$ & $p$ value \\
\hline Gender: male & $-0.397[-2.608$ to 1.741$]$ & 0.692 \\
\hline Age & $-0.028[-0.191$ to 0.055$]$ & 0.813 \\
\hline Body mass index & $-0.216[-0.426$ to 0.0169$]$ & 0.069 \\
\hline Hypertension & $0.738[-1.463$ to 3.181$]$ & 0.463 \\
\hline Diabetes & $-0.114[-3.083$ to 2.749$]$ & 0.910 \\
\hline Dyslipidemia & $-0.059[-2.330$ to 2.196$]$ & 0.953 \\
\hline Previous stroke & $0.649[-1.688$ to 3.318$]$ & 0.518 \\
\hline Current smoking & $-1.411[-3.734$ to 0.639$]$ & 0.163 \\
\hline Previous cardiac surgery & $-0.415[-4.173$ to 2.736$]$ & 0.679 \\
\hline Chronic dialysis & $1.940[-1.279$ to 14.99$]$ & 0.088 \\
\hline Preoperative eGFR & $0.074[0.036$ to 0.111$]$ & $<0.001^{*}$ \\
\hline Preoperative BNP & $-0.068[-0.469$ to 0.046$]$ & 0.568 \\
\hline Left ventricular ejection fraction & $0.177[-0.120$ to 0.494$]$ & 0.137 \\
\hline Preoperative anticoagulant & $-0.719[-3.004$ to 1.413$]$ & 0.475 \\
\hline Valve surgery & $0.620[-3.262$ to 6.203$]$ & 0.537 \\
\hline CPB duration & $-0.260[-0.538$ to -0.147$]$ & $0.028^{*}$ \\
\hline Aortic cross-clamping duration & $-0.109[-0.419$ to 0.067$]$ & 0.361 \\
\hline Nadir hematocrit & $0.179[-0.061$ to 0.321$]$ & 0.133 \\
\hline Mean CPB pressure & $0.042[-0.211$ to 0.201$]$ & 0.727 \\
\hline Ratio of $<\mathrm{CPB}$ pressure $60 \mathrm{mmHg}$ & $-0.184[-0.350$ to 0.144$]$ & 0.123 \\
\hline Ratio of $<\mathrm{CPB}$ pressure $50 \mathrm{mmHg}$ & $-0.057[-0.269$ to 0.174$]$ & 0.636 \\
\hline $\begin{array}{l}\text { Preoperative } \mathrm{MAP} \text { —-mean CPB } \\
\text { pressure }\end{array}$ & $-0.235[-0.427$ t6 0.172$]$ & $0.047^{*}$ \\
\hline Mean CPB flow index & $-0.190[-0.455$ to 0.115$]$ & 0.110 \\
\hline Vasopressors during CPB & $-0.134[-2.487$ to 2.175$]$ & 0.894 \\
\hline $\begin{array}{l}\text { Transfusions during CPB with } \\
\text { RBCs }\end{array}$ & $1.800[-0.332$ to 5.195$]$ & 0.082 \\
\hline Lactate level at CPB-0 $\mathrm{h}$ & $-0.094[-0.298$ to 0.070$]$ & 0.431 \\
\hline Lactate level at CPB-1 h & $-2.120[-4.566$ to 0.327$]$ & 0.088 \\
\hline Lactate level at CPB-2 $\mathrm{h}$ & $-2.646[-4.455$ to -0.837$]$ & $0.005^{*}$ \\
\hline
\end{tabular}

Data were shown as regression coefficients with $95 \%$ confidence intervals $(\mathrm{Cls})$, ratio of $<$ CPB pressure ${ }^{* *} \mathrm{mmHg}(\%)$ : (duration of lower than ${ }^{* *} \mathrm{mmHg}$ during $(\mathrm{PB} /$ total $\mathrm{CPB}$ time $) \times 100$

eGFR estimated glomerular filtration rate, $B N P$ brain natriuretic peptide, $C P B$ cardiopulmonary bypass, MAP mean arterial pressure, CPB-\#h \# $\mathrm{h}$ after CPB started ${ }^{*} p<0.05$

postoperative outcome rather than therapeutic intervention after CPB or during ICU stay.

In the present study, difference between preoperative MAP and mean CPB perfusion pressure was also significantly associated with ICU-free survival days. A previous study suggested that a drop in MAP by more than $26 \mathrm{mmHg}$ from preoperative blood pressure caused a 2.8fold increase in a risk of development of postoperative AKI [7]. It is likely that the patients with development of AKI stay in the ICU longer than those without AKI. The
Table 4 Multivariate association of preoperative and intra-operative variables with the ICU-free survival days

\begin{tabular}{lcl}
\hline Variable & Regression coefficient & $p$ value \\
\hline Preoperative eGFR & 0.086 & $<0.001^{*}$ \\
CPB duration & -0.107 & 0.278 \\
Preoperative MAP_mean CPB pressure & -0.083 & $0.015^{*}$ \\
Lactate level at CPB-2 h & -3.601 & $<0.001^{*}$
\end{tabular}

Model $R^{2}=0.387$; data were shown as $\beta$ regression coefficients

CPB cardiopulmonary bypass, MAP mean arterial pressure, $C P B$-\#h \# $\mathrm{h}$ after CPB started, eGFR estimated glomerular filtration rate

${ }^{*} p<0.05$

maintenance of adequate perfusion pressure during $\mathrm{CPB}$ is important for vital organ perfusion [19]. It has been suggested that relatively high perfusion pressure during CPB is preferable to prevent cerebrovascular and gastroenterological complications, especially in the patients with impaired autoregulation system due to arteriosclerosis [13]. Even if autoregulation system well regulates to maintain peripheral tissue circulation, CPB perfusion pressure seems to be more important to prevent peripheral tissue hypoperfusion under nonpulsatile flow. Recently, study suggested that not only high perfusion flow but also high perfusion pressure was necessary during $\mathrm{CPB}$ to protect the skeletal muscle [20]. It remains controversial which is more important for management of $\mathrm{CPB}$, pressure, or flow. However, the present study clearly demonstrates that it may be necessary to minimize the difference preoperative MAP and CPB perfusion pressure. Further study will be required to determine the cutoff point between them for postoperative morbidity.

Preoperative renal function also independently contributes to ICU-free survival days. A previous study suggested that preoperative serum creatinine was a predictor for postoperative renal complications and in-hospital mortality in patient undergoing cardiac surgery [6, 21]. In addition, it has also suggested that CPB duration would prolong in patients with preoperative renal insufficiency $[6,21]$. As patients requiring hemodialysis particularly have multiple comorbidities such as hypertension, angina pectoris, diabetes, hyperlipidemia, and cerebrovascular diseases with severe arteriosclerosis, these patients would need prolongation of CPB and extended ICU stay. Therefore, we also have to pay careful attention to preoperative renal function in cardiac surgical patients.

Mean ICU-free survival days in present study was 25 days in our institution. Furushima and colleagues [14] reported that maximum lactate levels measured after $\mathrm{CPB}$ was independently associated with ICU-free survival days. And other study also suggested that postoperative maximum lactate levels could be the predictors about cardiac surgical morbidity and mortality. Demers and colleagues [9] showed that the patient with peak intra-operative blood lactate levels higher than $4.0 \mathrm{mmol} / \mathrm{L}$ needed prolonged ICU stay 
longer than 5 days. Maillet and colleagues [10] suggested that blood lactate level of $3 \mathrm{mmol} / \mathrm{L}$ at ICU admission could indicate high risk of postoperative morbidity and mortality in cardiac surgical patients. In addition, they showed that the LOS was 3.8 days in early hyperlactatemia group and 1.9 days in normal lactate range group. Compared to ICU-free survival days calculated from the LOS in the previous reports, the present data were slightly different. This small discrepancy might be due to the difference in the ICU discharge criteria between each institution. Other pre- or intra-operative predictors for cardiac surgical morbidity were reported as follows: emergency case, reoperation, preoperative low cardiac output, and prolonged $\mathrm{CPB}$ duration $[2,6]$. In the present study, although emergency cases were excluded for the analysis, reoperation ( $p=0.679$ by univariate analysis), preoperative low cardiac output ( $p=0.137$ by univariate analysis), and CPB duration ( $p=0.028$ by univariate analysis but $p=0.278$ by multivariate regression analysis) were not recognized as significant. Therefore, although CPB duration might become significant with much larger sample size, others would not be predictors for postoperative morbidity and mortality in cardiac surgical patients.

The sample size of this study was small, but we performed post hoc analysis and the power of this study was $0.88(n=72, \alpha=0.05, r=-0.31$, correlated regression between ICU-free survival days and lactate level measured $2 \mathrm{~h}$ after $\mathrm{CPB}$ ). Therefore, we believe that the present data must be meaningful.

In conclusion, in addition to preoperative renal function and differences between preoperative MAP and CPB pressure, the lactate level at $\mathrm{CPB}-2 \mathrm{~h}$ could be a predictor of ICU-free survival days in patients undergoing cardiac surgery.

\section{Authors' contributions}

SN designed the study, analyzed and interpreted the data, and drafted the manuscript. JS reviewed the analysis of the data and edited the manuscript. $\mathrm{EH}$ and TK helped conduct the study. KH made substantial contributions to the conception and design of the study and helped in writing the manuscript and statistical analysis. All authors have read and approved the final manuscript.

\section{Competing interests}

The authors declare that they have no competing interests.

\section{Ethics approval}

This is a retrospective observational study approved by the Medical Ethics Committee of Hirosaki University Graduate School of Medicine (approval number 2015-168)

Received: 19 August 2016 Accepted: 15 November 2016

Published online: 24 November 2016

\section{References}

1. Messaoudi N, De Cocker J, Stockman B, Bossaert LL, Rodrigus IE. Prediction of prolonged length of stay in the intensive care unit after cardiac surgery: the need for a multi-institutional risk scoring system. J Card Surg. 2009;24:127-33.

2. Atoui $R, M a F$, Langlois $Y$, Morin JF. Risk factors for prolonged stay in the intensive care unit and on the ward after cardiac surgery. J Card Surg. 2008;23:99-106.
3. The Japanese Society of Intensive Care Medicine, Committee for Social Insurance. Revenue and cost in Japanese ICU focused on the use of lifesupport system and length of stay in the diagnosis procedure combination/ per-diem payment system. J Jpn Soc Intensive Care Med. 2013;20:431-4.

4. Helmerhorst HJ, Schultz MJ, van der Voort PH, Bosman RJ, Juffermans NP, de Wilde RB, van den Akker-van Marle ME, van Bodegom-Vos L, de Vries M, Eslami S, de Keizer NF, Abu-Hanna A, van Westerloo DJ, de Jonge E. Effectiveness and clinical outcomes of a two-step implementation of conservative oxygenation targets in critically ill patients: a before and after trial. Crit Care Med. 2016;44:554-63.

5. Young P, Saxena M, Bellomo R, Freebairn R, Hammond N, van Haren F, Holliday M, Henderson S, Mackle D, McArthur C, McGuinness S, Myburgh J, Weatherall M, Webb S, Beasley R, HEAT Investigators, Australian and New Zealand Intensive Care Society Clinical Trials Group. Acetaminophen for fever in critically ill patients with suspected infection. N Engl J Med. 2015;373:2215-24.

6. Salis S, Mazzanti W, Merli G, Salvi L, Tedesco CC, Veglia F, Sisillo E. Cardiopulmonary bypass duration is an independent predictor of morbidity and mortality after cardiac surgery. J Cardiothorac Vasc Anesth. 2008;22:814-22.

7. Kanji HD, Schulze CJ, Hervas-Malo M, Wang P, Ross DB, Zibdawi M, Bagshaw SM. Difference between pre-operative and cardiopulmonary bypass mean arterial pressure is independently associated with early cardiac surgeryassociated acute kidney injury. J Cardiothorac Surg. 2010:5:71.

8. O'Brien DJ, Alexander JA. Postoperative management of the adult cardiac surgery patient. In: Civetta JM, Taylor RW, Kirby RR, editors. Critical care. 3rd ed. Philadelphia, PA: Lippincott Williams \& Wilkins; 1997. p. 1147-75.

9. Demers P, Elkouri S, Martineau R, Couturier A, Cartier R. Outcome with high blood lactate levels during cardiopulmonary bypass in adult cardiac operation. Ann Thorac Surg. 2000;70:2082-6.

10. Maillet JM, Le Besnerais $P$, Cantoni M, Nataf $P$, Ruffenach A, Lessana A, Brodaty D. Frequency, risk factors, and outcome of hyperlactatemia after cardiac surgery. Chest. 2003;123:1361-6.

11. Hajjar LA, Almeida JP, Fukushima JT, Rhodes A, Vincent JL, Osawa EA, Galas FR. High lactate levels are predictors of major complications after cardiac surgery. J Thorac Cardiovasc Surg. 2013;146:455-60.

12. Ranucci M, Carboni G, Cotza M, Bianchi P, Di Dedda U, Aloisio T, the Surgical and Clinical Outcome Research (SCORE) Group. Hemodilution on cardiopulmonary bypass as a determinant of early postoperative hyperlactatemia. PLoS One. 2015;10:e0126939.

13. Plestis KA, Gold JP. Importance of blood pressure regulation in maintaining adequate tissue perfusion during caraiopulmonary bypass. Semin Thorac Cardiovasc Surg. 2001;13:170-5.

14. Furushima N, Egi M, Nakada Y, Ono D, Araki J. The association of intraoperative blood lactate concentrations with outcomes in adult cardiac surgery patients requiring cardiopulmonary bypass. Masui. 2014;63:846-50.

15. Shinde SB, Golam KK, Kumar P, Patil ND. Blood lactate levels during cardiopulmonary bypass for valvular heart surgery. Ann Card Anaesth. 2005; 8:39-44.

16. Svenmarker $S$, Häggmark $S$, Ostman $M$. What is a normal lactate level during cardiopulmonary bypass? Scand Cardiovasc J. 2006;40:305-11.

17. Kogan A, Preisman S, Bar A, Sternik L, Lavee J, Malachy A, Spiegelstein D, Berkenstadt H, Raanani E. The impact of hyperlactatemia on postoperative outcome after adult cardiac surgery. J Anesth. 2012;26:174-8.

18. O'Connor E, Fraser JF. The interpretation of perioperative lactate abnormalities in patients undergoing cardiac surgery. Anaesth Intensive Care. 2012:40:598-603.

19. McNicol L, Lipcsey M, Bellomo R, Parker F, Poustie S, Liu G, Kattula A. Pilot alternating treatment design study of the splanchnic metabolic effects of two mean arterial pressure targets during cardiopulmonary bypass. $\mathrm{Br} \mathrm{J}$ Anaesth. 2013:110:721-8.

20. Lonsky V, Svitek V, Brzek V, Kubicek J, Volt M, Horak M, Mandak J. Direct oxymetric peripheral tissue perfusion monitoring during open heart surgery with the use of cardiopulmonary bypass: preliminary experience. Perfusion. 2011:26:510-5.

21. Lin CY, Tsai FC, Chen YC, Lee HA, Chen SW, Liu KS, Lin PJ. Correlation of preoperative renal insufficiency with mortality and morbidity after aortic valve replacement: a propensity score matching analysis. Medicine. 2016;95:e2576. 